results obtained when antifungal drugs were combined with surgery. Taking nine patients managed this way from published reports together with 11 of their own the mortality was $20 \%$.

The Los Angeles team advocate surgery within 48 hours of diagnosis (thus minimizing the time during which the organism may grow into the myocardium), with removal of the infected valve and irrigation of the infected site with a solution of amphotericin B ( $1 \mathrm{~g}$ per litre of Ringer's solution) for a period of 15 minutes before the prosthetic valve is inserted. After operation they recommend a prolonged course of amphotericin B given intravenously in a dose of $10 \mathrm{mg}$ increasing to $50 \mathrm{mg}$ if tolerated, three times weekly, possibly up to a total dose of $2500 \mathrm{mg}$.

Experience of this condition has shown that its diagnosis constitutes a surgical emergency, and that few patients will survive with chemotherapy alone.

\footnotetext{
1 Joachim, H., and Polayes, S. H., Fournal of the American Medical Association, 1940, 115, 205.

2 Seelig, M. S., et al., Progress in Cardiovascular Diseases, 1974, 17, 125.

3 Ouchterlony, O., in 6th International Congress for Microbiology, vol. 11, p. 276. Rome, 1953.

Remington, J. S., Gaines, J. D., and Gilmer, M. A., Lancet, 1972, 1, 413.

5 Hellwege, H. H., Fischer, K., and Blaker, F., Lancet, 1972, 2, 386.

6 Record, C. O., et al., British Medical fournal, 1971, 1, 262.

7 Kay, J. H., et al., fournal of the American Medical Association, 1968, 203, 621 .

8 Braimbridge, M. V., Lancet, 1969, 1, 1307.

9 Chaudhuri, M. R., Fournal of Thoracic and Cardiovascular Surgery, 1970, $60,207$.

10 Engelman, R. M., et al., Annals of Surgery, 1971, 173, 455.

11 Seelig, M. S., et al., fournal of Thoracic and Cardiovascular Surgery, 1973, $65,583$.

12 Turnier, E., et al., Chest, 1975, 67, 262.
}

\section{Restrictions on Coroners' Juries}

A Bill is to be introduced into the House of Commons to abolish the duty of coroners' juries to return verdicts of murder or manslaughter against a named individual and the coroner's duty to commit that person for trial. Lord WellsPestel, speaking for the Government, announced this in the Lords last week. ${ }^{1}$

Everyone with a concern for justice will welcome this long overdue proposal. It is a centuries-old duty of a coroner's jury in cases of murder, manslaughter, and infanticide to name the person they consider to have been guilty of the crime, and the coroner has a consequential duty to commit him for trial. The Brodrick report ${ }^{2}$ did no more than reflect the common opinion today in its condemnation of this procedure. The difficulty of ensuring a fair trial for a person who has already had a verdict of guilty hung round his neck has long been acknowledged. Furthermore, the coroner's jury often reaches its verdict on evidence that would never be allowed in a criminal court.

Several recent cases have focused attention again on this mediaeval anachronism, not least the one concerning two doctors discussed by our Legal Correspondent in the B.M.F. three weeks ago. ${ }^{3}$ The inquest was on a boy of 2 years who had died after an operation for peritonitis. Both doctors told the coroner they had diagnosed gastroenteritis. After a three-day inquest the jury returned a verdict of manslaughter and the coroner committed the two doctors for trial on the charge. ${ }^{4}$ When the trial came on the Crown offered no evidence against them and they were discharged. But the ordeal to which they had been subjected included having to face in the coroner's court what the Medical Defence Union" described as "a mass of evidence which was highly prejudicial and clearly inadmissible in any criminal court or even in a civil court."

It is to prevent the repetition of injustices of this kind that the Bill deserves a swift passage.

1 House of Lords Hansard, 23 July 1975, col. 324.
2 Report of the Committee on Death Certification and Coroners, Cmnd. 4810.
London, H.M.S.O., 1971.
${ }^{3}$ British Medical fournal, 1975, 3, 108.
${ }^{4}$ British Medical Fournal, 1975, 2, 287.

\section{Aetiology of Optic Neuritis}

The aetiology of optic neuritis continues to cause uncertainty. The proportion of patients whose first symptom of neurological disease is optic neuritis and who later develop symptoms and signs of definite multiple sclerosis has variously been reported $^{12}$ to lie between $11.5 \%$ and $85 \%$. In a further large series of studies of cases of optic neuritis reported from Finland, $50 \%$ were reported to develop probable multiple sclerosis during an average follow-up period of 10 years. ${ }^{34}$ If, then, only a proportion of patients with optic neuritis later develop indications of multiple sclerosis it would be helpful for prognosis to have some test to distinguish them.

Many centres have reported that antibodies to measles (and to a lesser extent other viruses) are increased both in frequency and in level in the serum of patients with multiple sclerosis when compared with controls. Similarly, patients with multiple sclerosis ${ }^{5-7}$ have a higher incidence and higher levels of measles antibodies in the cerebrospinal fluid and a decreased ratio of serum/C.S.F. antibody levels. Link et al. $(1973)^{8}$ were able to divide their patients with optic neuritis into two groups on the basis of the presence of oligoclonal IgG in the C.S.F., which is commonly found in multiple sclerosis patients. The implication is that multiple sclerosis is likely to develop in patients with optic neuritis whose C.S.F. shows changes like those found in multiple sclerosis. Such a postulate cannot, however, be accepted until proved by careful follow-up. Arnason et al. ${ }^{9}$ studied HL-A and other antigens in patients with optic neuritis and multiple sclerosis and suggested that the two conditions had differing genetic backgrounds; but a recent study has been unable to confirm these findings. ${ }^{10}$

These theoretical possibilities should not be allowed to obscure the practical points of importance. By no means all cases of optic neuritis are due to multiple sclerosis, and a number of other causes, particularly in the older patients, should be remembered. These include diabetes, pernicious anaemia, optic nerve compression, chronic meningitis, and vascular diseases including arteriosclerosis and arteritides. ${ }^{311-13}$ It is also worth remembering that multiple sclerosis has an overall prognosis which is relatively milder than was once believed, ${ }^{14}$ and that patients with multiple sclerosis originally presenting with optic neuritis have an even better prognosis for mortality and disability. ${ }^{15-17}$

1 Kurland, L. T., et al., Acta Neurologica Scandinavica, 1966, Suppl. 19, 157.

2 Lynn, B. H., Transactions of the Ophthalmological Society of the United Kingdom, 1959, 79, 701. Adapted by McAlpine, D., British Medical fournal, 1964, 2, 1029.

${ }^{3}$ Nikoskelainen, E., and Riekkinen, P., Acta Neurologica Scandinavica, $1974,50,690$.

4 Nikoskelainen, E. Dissertation to the Medical Faculty of the University of Turku, 1975.

5 Winchester, J. S., and Hambling, M. H., fournal of Medical Microbiology, $1972,5,137$.

6 Salmi, A. A., Annals of Clinical Research, 1973, 5, 319. 
7 Nikoskelainen, E., et al., Acta Neurologica Scandinavica, 1975, 51, 347.

${ }^{8}$ Link, H., Norrby, E., and Olsson, J.-E., New England fournal of Medicine, $1973,289,1103$.

- Arnason, B. G. W., et al., fournal of the Neurological Sciences, 1974, 22, 419.

10 Platz, P., et al., Lancet, 1975, 1, 520.

11 Bradley, W. G., Diseases of the Nervous System, 1968, 29, 668.

12 Ellenberger, C., Keltner, J. L., and Burde, R. M., Archives of Neurology, 1973, 28, 182.

13 Schlezinger, N. S., and Thompson, R. A., Neurology, 1967, 17, 782

14 Percy, A. K., et al., Archives of Neurology, 1971, 25, 105.

15 Bradley, W. G., and Whitty, C. W. M., fournal of Neurology, Neurosurgery and Psychiatry, 1968, 31, 10.

${ }^{16}$ McAlpine, D., Lumsden, C. E., and Acheson, E. D., Multiple Sclerosis: a Reappraisal, 2nd edn. London, Churchill Livingstone, 1972.

17 Fog, T., and Linneman, F., Acta Neurologica Scandinavica, 1970, suppl. 47.

\section{Blowing in the Wind}

On the same day as a recent newspaper report ${ }^{1}$ appeared with the heading "Hang gliding supporters happy about safety" an article in F.A.M.A. ${ }^{2}$ described four deaths from the sport. Taking a risk has always had its attractions, so that the two reports are not incompatible, but they do serve to draw attention to the fast growing popularity of a pastime that in various forms has a history stretching back over centuries and in its present form has been described as "a high-risk leisure-time activity."3

A hang glider consists of a sail spread over a more or less rigid triangular frame. Models vary in the complexity of their construction and in the provision made for control of the flight. In the simplest forms this is done by body movements alone. The machine is therefore a kite rather than a parachute, and the pilot sits or lies prone in a harness beneath it. To launch himself he usually runs a short distance down a steep hill and pushes forward a control bar, then eases it and floats away. To land he brings the glider down nearly parallel to the ground, and if all goes well he almost comes to a halt in the air as he touches down. ${ }^{4}$

The first need is for technically faultless equipment. In this as in many other ways the clubs now springing up can have a healthy influence in seeing that their members use wellconstructed gliders, which will nearly always mean gliders commercially made by a few firms. The choice of flying site is not so easy as would first appear ${ }^{4}$ and requires experienced judgement. But perhaps the most difficult question that every hang glider must answer is whether the weather is suitable when he wants to take off. Here the experience that clubs accumulate can be of enormous help to novices. For undoubtedly the gusty days that make up so much fine weather in Britain must offer hazards as well as thrills. A further and equally important influence on the pilot's safety must be his own personality. Many people are by nature rash, or easily upset by quarrels, or prone to show off to their friends. Perhaps the least of the natural hazards is inexperience. Of the four men whose deaths are reported by Krissoff and Eiseman, ${ }^{2}$ three were exceptionally experienced and one moderately so. What seemed to contribute mainly to their deaths were, in one case each, taking a great risk deliberately, emotional upset because of a break-up with the girl friend, a rash decision to fly in turbulent wind, and drinking alcohol before flying.

In Paris at the end of June the first international meeting of hang glider pilots formed the Commission of Hang Gliding, ${ }^{5}$ which now awaits formal acceptance by the Federation Aeronautique Internationale. One way in which this commission can help to promote safety is through the rules it permits for competitive hang gliding. Some forms of competition are more dangerous than others, and if needless risk of this kind is debarred from international recognition it will soon be discouraged in the clubs. There was evidence at the meeting that the commission is already looking in this direction.

1 The Times, 14 July 1975.

${ }^{2}$ Krissoff, W. B., and Eiseman, B., Fournal of the American Medical Association, 1975, 233, 158.

3 Eiseman, B. Fournal of the American Medical Association, 1975, 233, 171.

4 Jarrett, P., and Kent, D., Flight International, 14 May 1974, p. 593.

5 Flight International, 17 July 1975, p. 77.

\section{Retirement of Editor}

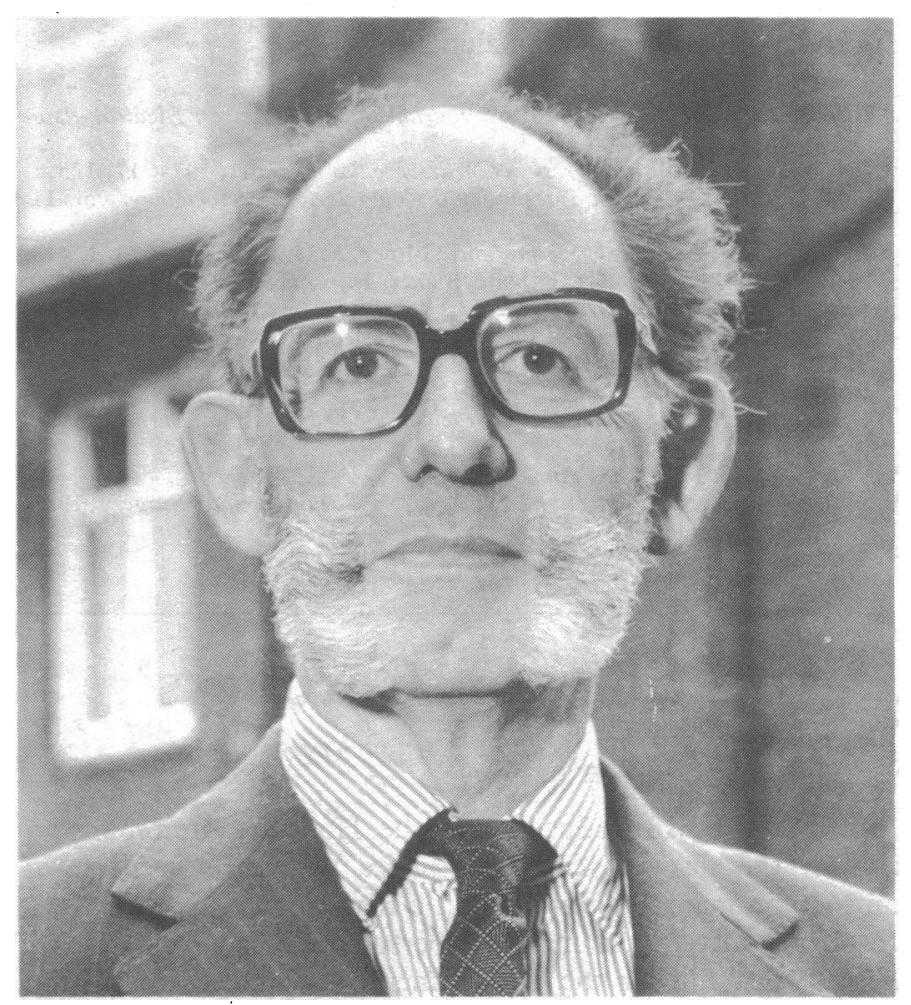

After serving as Editor of the $B$. $M . \mathcal{F}$. for nine and a half years Dr. Martin Ware retired this week. In several ways these years have brought substantial changes in the way the journal attempts every week its task of providing something for everyone. Most notably the middle pages have given space to a much greater variety of articles on administrative, social, and economic themes than formerly, for these aspects of medicine have become inseparable from so much of today's practice. At the same time the Supplement has developed a more newsy, selective, and at times personal idiom to lighten its reports of medical politics. But the main burden of editorship has perhaps been less evident to many readers. Two changes of printers have had to be undertaken-always a traumatic experience for editorial staffs. A long libel action had to be defended to vindicate the right of the medical press to publish in good faith articles of scientific importance to doctors. And latterly the evils of inflation accompanied by staggering rises in costs have added their worries to the more conventional vexations that irate authors (or failed authors) lay up for the editor. In recognition of his work the Association has made Dr. Ware a vice-president, and the good wishes of innumerable friends will go with him in his retirement. His successor is Dr. Stephen Lock (page 316). 